\title{
Improving medication adherence: a framework for community pharmacy-based interventions
}

This article was published in the following Dove Press journal:

Integrated Pharmacy Research and Practice

16 November 2015

Number of times this article has been viewed

\author{
Janice Pringle \\ Kim C Coley ${ }^{2}$ \\ 'Program Evaluation and Research \\ Unit, Department of Pharmacy and \\ Therapeutics, School of Pharmacy, \\ University of Pittsburgh, Pittsburgh, \\ PA, USA; ${ }^{2}$ Department of Pharmacy \\ and Therapeutics, School of Pharmacy, \\ University of Pittsburgh, Pittsburgh, \\ PA, USA
}

Abstract: Evidence supports that patient medication adherence is suboptimal with patients typically taking less than half of their prescribed doses. Medication nonadherence is associated with poor health outcomes and higher downstream health care costs. Results of studies evaluating pharmacist-led models in a community pharmacy setting and their impact on medication adherence have been mixed. Community pharmacists are ideally situated to provide medication adherence interventions, and effective strategies for how they can consistently improve patient medication adherence are necessary. This article suggests a framework to use in the community pharmacy setting that will significantly improve patient adherence and provides a strategy for how to apply this framework to develop and test new medication adherence innovations. The proposed framework is composed of the following elements: 1) defining the program's pharmacy service vision, 2) using evidence-based, patient-centered communication and intervention strategies, 3) using specific implementation approaches that ensure fidelity, and 4) applying continuous evaluation strategies. Within this framework, pharmacist interventions should include those services that capitalize on their specific skill sets. It is also essential that the organization's leadership effectively communicates the pharmacy service vision. Medication adherence strategies that are evidence-based and individualized to each patient's adherence problems are most desirable. Ideally, interventions would be delivered repeatedly over time and adjusted when patient's adherence circumstances change. Motivational interviewing principles are particularly well suited for this. Providing effective training and ensuring that the intervention can be delivered with fidelity within a specified workflow process are also essential for success. Utilizing this proposed framework will lead to greater and consistent success when implementing pharmacistled medication adherence interventions in the community pharmacy setting.

Keywords: medication adherence, community pharmacy services, pharmacies, implementation science

\section{Introduction}

There is consistent evidence that patient medication adherence is poor, with an expectation that patients typically take less than half of their prescribed doses. ${ }^{1-3}$ Inadequate medication adherence has been associated in a number of studies and meta-analyses with poor health outcomes, ${ }^{4,5}$ mortality, ${ }^{6}$ and even higher downstream health care costs, largely reflected via increased hospitalizations and emergency department utilizations. ${ }^{7-9}$ There have been a plethora of studies published internationally, regarding the effectiveness of various pharmacist-led interventions on adherence for community-dwelling patients. ${ }^{10-12}$ Some of these studies have indicated a significant impact of pharmacist-led interventions on patient medication adherence, whereas others have demonstrated no significant effect. ${ }^{13,14}$ Since community pharmacists are
Correspondence: Janice Pringle 5607 Baum Boulevard, Suite 53I, Pittsburgh, PA 15206, USA

Tel +l 4I 23832005

$\mathrm{Fax}+\mathrm{I} 4123832090$

Email jlpringle@pitt.edu 
ideally positioned to provide patient-centered medication adherence interventions as the majority of patients receive their medications from a community pharmacy, ${ }^{15}$ it would be important to suggest strategies for how pharmacists could consistently improve patient medication adherence either alone or in collaboration with other allied health care providers. This article suggests a framework that, based on the published evidence, can be used by community pharmacists to significantly improve patient adherence and to provide a strategy for how this framework can be used to develop and test new pharmacy innovations. It is important to note that this framework is intended to be applied in total. Every component should be applied as indicated to achieve a consistent improvement in patient adherence.

\section{Proposed framework}

The proposed framework is composed of the following elements: 1) Defining the program's pharmacy service vision any community pharmacy intervention should be designed and implemented using pharmacy services that are aligned with the pharmacist's key skills that have been demonstrated effectively in improving patient medication adherence beyond other health care providers. 2) Using evidence-based, patientcentered communication and intervention strategies - the intervention should include evidence-based, patient-centered communication strategies alone or in conjunction with other interventions; additionally, the intervention should include evidence-based approaches that are matched to each patient's needs and unique characteristics (ie, age, sex, ethnicity, psychosocial status, values, and beliefs). 3) Using specific implementation approaches that ensure fidelity - the intervention should be implemented so that every pharmacist can provide it consistently with fidelity. 4) Applying continuous evaluation strategies - the intervention should be continuously evaluated and improved so that it can achieve optimal patient clinical outcomes. Figure 1 describes the framework elements and their proposed association in developing effective pharmacy-led interventional strategies that aimed at improving medication adherence.

For the purpose of this article, we are defining community pharmacists as pharmacists practicing in a community-based pharmacy location, such as a chain, supermarket, mass merchant, or independent pharmacy. We are defining medication adherence as the extent to which patients take medications as prescribed by their health care providers. ${ }^{1}$ We are also defining patient-centered communication strategies as those that encompass qualities of compassion, empathy, and responsiveness to the needs, values, and expressed preference of the individual patient. ${ }^{16} \mathrm{~A}$ patient-centered methodology focuses on the patient as a unique person rather than taking a "one size fits all" approach. Effective evidence-based strategies are those that integrate strategies with proven positive effects

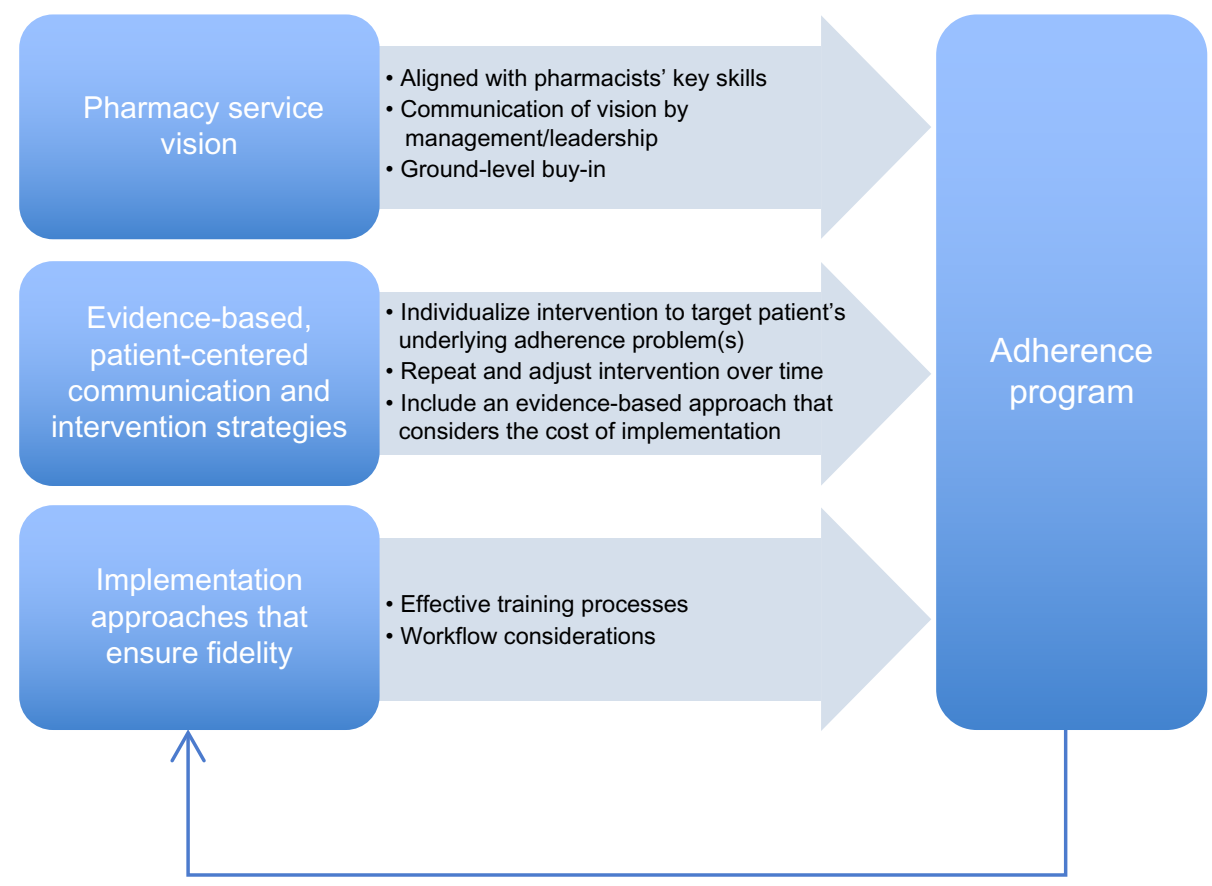

Continuous evaluation strategy

Figure I Adherence invention framework. 
using rigorous research methodologies and reported in peerreviewed journals. ${ }^{17}$ Finally, we are defining implementation as the use of strategies to adopt and integrate evidence-based health interventions. ${ }^{18}$ Given these definitions, the following sections further characterize the framework components.

\section{Framework components}

\section{Pharmacy service-based vision}

Community pharmacist-provided patient care services often have suffered from a poorly defined professional vision that fails to capitalize on the knowledge and skill set pharmacists possess over other health care team members. ${ }^{19,20}$ Pharmacists often find themselves in conflict with other health care providers (eg, nurses and physicians), regarding whether their medication-related services are superior in clinical impact while remaining cost-effective. ${ }^{21,22}$ There is some evidence that pharmacists are the best suited health care professionals at providing the following medication-related services: 1) determining the most effective and parsimonious list of medications clinically appropriate to a patient; ${ }^{21,23} 2$ ) working with patients to increase their health literacy regarding their medications $;{ }^{24}$ and 3) facilitating patient motivation to take their medications as directed. ${ }^{10,25}$ Successful community pharmacist-led interventions that are targeting medication adherence improvement should involve pharmacy services that encompass these three elements. When pharmacists provide other services (such as health behavior coaching) to the detriment of providing the abovementioned three services, they may be less likely to have a positive impact on patient medication adherence. ${ }^{13}$ It is also strongly suggested that when other allied health care providers (ie, nurses) provide these three services, pharmacists should supervise the provider training and provide ongoing clinical supervision and consultation. ${ }^{26}$

This community pharmacy service vision will be most effective in guiding the implementation of a medication adherence-associated intervention program when all of the pharmacists, pharmacy technicians/staff, pharmacy leaders, collaborating health care providers, and other stakeholders involved fully understand and embrace it. An unequal commitment to this vision by pharmacy service leadership or an inadequate communication of this vision among professionals working within and outside of pharmacy services will likely result in an unsuccessful implementation of a medication adherence-focused intervention. The pharmacy leadership should consistently and extensively communicate this pharmacy service vision, empowering the pharmacy team members to advance the vision to other allied health care providers. ${ }^{27}$ When pharmacy service providers (eg, pharmacists, pharmacy technicians, and pharmacy administers) are clear regarding what services they can best provide to support patient medication adherence, then this will clear the way for other allied health care providers to provide services that may wrap around those provided by pharmacists further supporting patient medication adherence.

\section{Evidence-based, patient-centered intervention strategies}

Each patient has specific underlying demographic, behavioral, psychological, economic, and social reasons for why he/she may not obtain or take a particular medication, and these reasons can change over time. ${ }^{28-33}$ It is not an accurate assumption that patient medication adherence problems are mostly associated with forgetfulness. ${ }^{34}$ Patients largely forget to take their medications because the medications do not have a level of importance or meaning that would support remembering to use them. ${ }^{35}$ The most effective interventional approaches help the patient discover their medication's meaning in terms that are only relevant to them..$^{11,36,37}$ Thus, approaches that address forgetfulness for why patients may not take their medications (ie, automated refill reminders, text messaging, and pill boxes) may result in temporary adherence improvements among a small number of patients, but these approaches will fail to consistently motivate a significant proportion of patients who require individualized strategies that target more fundamental underlying reasons (ie, denial of the disease that requires the medication, fear of medication side effects, and cost of medication). ${ }^{38}$ The impact of these repeated reminder-based interventions would lessen over time as the patient's circumstances change or when they fatigue to the intervention's impact. ${ }^{38}$ What is even more important is that the patients who are not affected by these interventions will likely experience worsening adherence, resulting in poor health outcomes. Thus, the most effective strategies for addressing patient medication adherence will 1) accurately identify the patient's current adherence risk status; 2) identify the underlying reasons why the patient is ambivalent to take his/her medications at any given time point; 3) identify the patient's individual behaviors, values, and beliefs that are associated with these underlying reasons for nonadherence; 4) match effective interventional strategies to each patient given his/her adherence risk status, reasons for ambivalence, and the values/beliefs surrounding these reasons; and 5) repeat these processes over time realizing that patients' adherence risk and reasons/behaviors/values/beliefs surrounding medication adherence ambivalence can change and thus require 
repeated and/or different interventions over time. Indeed, adherence interventions that follow this approach and that are delivered to a given patient over a longer period of time are more likely to achieve the intended outcome. ${ }^{39}$

The use of interventions based on motivational interviewing or motivational interviewing principles has been successful in improving medication adherence when provided by pharmacists. ${ }^{10}$ Motivational interviewing techniques are also perfectly suited to identify time-dependent reasons why patients may be ambivalent about taking their medications, facilitate the patient's motivation to improve his/her adherence, and determine what additional interventions might best support the patient's adherence..$^{10,11,40,41}$ Motivational interviewing medication counseling is an evidence-based intervention that requires extensive training by certified trainers, while the use of motivational interviewing principles in patient communications requires far less training and employs similar strategies to motivational interviewing counseling but at a lesser scope. This is because motivational interviewing principles (ie, express empathy, develop discrepancy, role with resistance, and support self-efficacy) do not require specific domain knowledge to use. ${ }^{42}$ Instead, they focus on promoting a behavioral change that can be applied to a wide array of patient's health behaviors seen across a variety of health disciplines. It is also important to note that the patient's reasons for ambivalence toward medication adherence can become more and more deeply understood with repeated interventions over time, leading to increasingly more effective strategies for improving the patient's motivation to improve his/her adherence and more effective linking of the patient to additional interventions. ${ }^{19}$ For this reason, documentation using a system, such as an electronic health record (EHR), is a vital component in this process. An EHR will enable the pharmacist to record the results of patient-centered communications, and the strategies the pharmacist and patient agree will be tried until the next encounter. Additionally, use of an EHR can be used to chronicle the patient's underlying reasons for why he/she is ambivalent about adhering to his/her medication regimen.

Understanding which type of intervention to match to any given patient at any given point in time is something that is in its infancy with pharmacy services and many other health care areas. ${ }^{43,44}$ Additional interventions that are currently being developed include at-home visits and monitoring, ${ }^{45,46}$ interdisciplinary care management, ${ }^{47,48}$ and interactive technological applications, ${ }^{49,50}$ among others. Ongoing rapid cycle evaluation and research efforts that systematically elucidate how to effectively match interventions to patients of given time-dependent risk characteristics need to be developed to support these pharmacy interventional efforts. Finally, as more accurate and responsive predictive analytic methods are developed involving various sources of patient-level data, understanding how to best quantify patient risk and categorize patients with respect to how they respond to specific interventions will become easier to accomplish, ${ }^{51,52}$ These methods could theoretically guide pharmacists in real time to implement increasingly more effective adherence interventions for individual patients and across patient populations, improving patient and population health and decreasing downstream health care costs.

There are also practice considerations in determining what intervention might best be applied for any given patient or patient population as there is an international need to control and reduce health care costs while improving patient care and outcomes. ${ }^{16,53-55}$ Thus, health care providers, payers, and purchasers must be ever cognizant of the cost of implementing an intervention that is balanced by its effectiveness. There are formal ways that this can be assessed via cost-effectiveness or return on investment studies, and these are of course recommended. ${ }^{56-58}$ When these studies are not available, results from similar studies can be used to determine the likelihood that a given intervention will result in decreased costs, while improving patient care and outcomes. These studies need to be carefully reviewed to determine the level of evidence that exists to recommend the intervention for the specific population and circumstances being targeted. There are a number of reviews that can assist with this evaluation. ${ }^{5,59,60}$ In the absence of these reviews, basic research literacy approaches can be used to assess the level of scientific rigor that would recommend or not recommend a given intervention. ${ }^{61,62}$

\section{Implementing the intervention with fidelity}

When considering the cost of implementing an evidencebased intervention, it is important to have a goal that the intervention will be implemented so that pharmacists can provide it with fidelity every time they use the intervention. ${ }^{63,64}$ The intervention can then be effectively spread to other pharmacists within the targeted pharmacy organization and continuously improved both in its implementation and in its effectiveness (ie, the development of practice-based evidence). ${ }^{65,66}$ The achievement of this goal involves the use of an implementation framework that includes the following components. 1) An understanding that the program's goal is to provide every patient with the proper and effective intervention every time. It is important that all persons involved embrace this inclusive vision so they design and implement 
the work to ensure that every patient receives effective services. 2) Implementing effective training processes that ensure all pharmacists have learned the necessary knowledge and can demonstrate the targeted skills associated with the intervention with proficiency. Each pharmacist must receive training that ensures he/she can provide the intervention in line with the evidence. This means that the training should follow the tenets of what the developer feels or the literature indicates is important. The pharmacist should be able to demonstrate they are proficient in providing the intervention along these factors defined from the evidence. ${ }^{67,68}$ The pharmacists can demonstrate skill-based proficiency by role-playing the intervention in front of a trained assessor who evaluates their skills using a proficiency checklist that contains the skill targets associated with the intervention according to the literature or the developer. ${ }^{69}$ Two major problems with having a practitioner applying an intervention in practice are the practitioner's lack of confidence (or self-efficacy) in applying his/her new skills with a patient and the potential skill loss over time if the practitioner does not utilize the skill on a regular basis. ${ }^{70}$ These obstacles can be obviated by providing additional training until the practitioner can demonstrate expert proficiency (via a proficiency checklist) or having an expertly trained staff person (often called "super users", site champions, or preceptors) to provide feedback to the practitioner in applying his/her new skills in the worksite. ${ }^{26,71,72}$ These organizational experts or super users would need to periodically view the pharmacists providing the interventions using a similar evidence-based proficiency checklist to ensure that the pharmacists' skills do not decay over time. This is an essential step in ensuring that the intervention is provided consistently, as it can often take 2 months of consistent application before a practitioner applies the intervention consistently and with fidelity. 3) Ensuring that implementation occurs in a manner that permits fidelity within a highly specified workflow process each time the pharmacist applies the intervention. When an intervention is poorly defined within the workflow, it will not be applied consistently regardless of how well the pharmacists are proficient in applying the skills associated with the intervention. ${ }^{73}$ Often pharmacy organizations do not specify sufficiently how the intervention will be provided. These specifications should include: a) who will provide the intervention, b) when and how the intervention will occur with respect to the patient care process - including other clinical services being offered, c) where the intervention will occur (eg, in a private area in the pharmacy), d) how the intervention will be applied, e) how frequently the intervention will occur, and f) in what sequence will the intervention be applied. The degree to which these issues can be specified before implementation will alleviate the inevitable chaos and implementation failure that will occur in the absence of this specification. 4) By developing the internal capacity to spread the innovation, each pharmacist is implementing the innovation with consistent fidelity across the organization. ${ }^{74}$ In this latter point, it is again highly recommended that an organization invest in having super users who will consistently and systematically monitor on a consistent basis each pharmacist's ability to implement the innovation with fidelity and train new pharmacists who come into the system. ${ }^{75}$ Super users can also lead instructive case discussions and even conduct case supervision sessions. The cost for including super users into the system must be considered in determining the cost of the intervention. Innovations that are more complex will require more intensive super user oversight. Super user costs can be obviated with more comprehensive pharmacist training at the project's front end, ensuring that pharmacists leave the training with close to expert proficiency in the desired skills and have the confidence to begin the planned intervention. However, this additional training cost (especially when a large workforce requires training) can be greater than the additional super user costs necessary to support less prepared pharmacists. It is also important to phase in an implementation so that it begins with sites that are organizationally more ready to take on the innovation and leverage the success of these sites to those that may require more support. ${ }^{76}$ Many health care organizations fail to utilize this phasing approach when implementing an innovation and realize either a small percentage of targeted units implementing the innovation over time or a total decay of the innovation's effectiveness. ${ }^{60,77}$ The consistent and conscientious application of these principles when implementing an innovation will, in our experience, see stable and consistent implementation within a few months in most organizations. ${ }^{10}$

\section{Applying a continuous evaluation strategy}

Many health care sites will implement an intervention but fail to evaluate its uptake among targeted sites and its impact on patients. Implementation checklists that assess each site's status with respect to implementing an innovation and proficiency checklists can be used to measure uptake. Organizational super users can use implementation and proficiency checklists during site visits and/or phone interviews to obtain data with respect to each site and practitioner's intervention use. ${ }^{78,79}$ The collection of these data should be more frequent during the intervention's startup phase, which 
typically encompasses the first 2-3-month period. Typically, these data should be collected weekly for proficiency checklists and bimonthly for implementation checklists during the startup phase. After the sites have reached steady state, the collection of these data can become less frequent (monthly). The data collected from these processes should be reviewed immediately and remedial action provided to and negotiated with either the practitioner (proficiency) or the site (implementation) so that proficiency and steady implementation can be resumed. Additional data should also be collected such as the number of patients who receive any aspect of the planned intervention compared to the expected/planned number of patients and the interim impact of the interventions upon adherence and other relevant outcomes. With the former data point, any significant deviations from the expected number of provided interventions would require swift investigation and remediation to ensure that the program continues as planned. With the latter data points, an evaluation of how patients may or may not respond to the intervention can provide valuable information regarding how to improve the intervention or develop new interventions that can be tested at a later date.

\section{The application of the framework}

Based on the abovementioned suggestions, we have summarized how the proposed framework can be used to implement interventions aimed at improving patient adherence. We are suggesting the following process when applying the abovementioned framework:

1. The pharmacy organization and other organizations (if appropriate) meet to discuss and fully adopt the pharmacyfocused services described earlier as the vision for how pharmacy will be involved in the service model. The vision for how the pharmacy services will be provided as well as the vision for any other allied health care providers (if appropriate) is then described in detail and agreed to by all.

2. A strategy is developed to determine the best sites/ organizations where implementation should begin. Organizational assessments can be used to determine sites that have the most desired characteristics such as strong stable leadership, defined work processes, low staff turnover, and an organizational culture that values learning and patient-centered care. Sites strongest in these characteristics should typically be the first to implement the intervention, as they are most likely to be successful. Once these sites are successful, their results can be used to leverage the next strongest sites until most of the sites have implemented the intervention. It should be noted that based on what we know about the diffusion of innovations, there will likely be a small percentage of sites $(5 \%-10 \%)$ that will not be able to implement the innovation because they do not have the qualities to do so (mostly they do not have appropriate leadership). In the case of these sites, the leadership will likely need to be changed in order to ensure appropriate implementation of the intended innovation.

3. Baseline patient data with respect to adherence is reviewed to determine the population demographics, medication classes involved, baseline medication adherence, and gaps in adherence that would need to be addressed.

4. The team adopts and becomes proficient in a patientcentered communication strategy that will be the basis for the intervention or will be the platform from which additional interventions can be provided. These communication strategies can include motivational interviewing principles or motivational interviewing counseling. Based on the population demographics, medication classes targeted, and other factors, an evidence-based patient-centered interventional approach is chosen that links an evidence-based intervention that maps to each patient's evolving adherence risk, health behaviors/values/ beliefs.

5. The team uses training principles that ensures each practitioner is proficient in applying the patient-centered intervention strategy and provides suitable training. A train-the-trainer approach should be considered for large community pharmacy organizations because it provides a more efficient use of resources when large numbers of individuals need to be trained. It also builds a team of instructors that will be able to provide the training over a shorter period of time. Finally, and most importantly, it places the training into the context of the organization and improved the relevancy to the end users. Designated super users can ensure that the intervention strategies are applied consistently and effectively with targeted patients and that each patient who is eligible for these interventions receives them.

6. A comprehensive implementation approach is designed that includes pharmacists training, organizational preparation and training, detailed workflow roll out, follow-up, and assistance, performance measures to ensure fidelity and a process for tracking movement toward an intended goal for each patient, and outcome evaluations that support sustaining the intervention/program.

7. A comprehensive plan for sustaining and spreading the innovation is developed and implemented at the start 
of the program, which will permit the program to be sustained, spread, and improved. This plan may involve including payers/purchasers in the development and evaluation of the program.

\section{Possible barriers to applying the framework}

Based on our experience in having applied the framework proposed both within and outside of pharmacy practice (viz, over 400 pharmacists, 100 physicians, 250 nurses, and numerous medical support staff), we have considerable experience in understanding the barriers to its implementation. The most significant barrier is obtaining the resources from the pharmacy necessary to ensure that any implementation of the targeted adherence intervention is applied as designed (with fidelity). The minimal resources required include: 1) access to the pharmacy or pharmacy organization senior management to ensure that the management agrees to the program's ultimate vision, to provide the resources required to support implementation as specified by the framework, and to be involved on an ongoing basis with monitoring the project's progress and support its implementation; 2) identification and commitment of site or organizational champions who will be trained to provide training and oversee the program's implementation using the framework; 3) training time for the pharmacists; and 4) collection of data that can be used to guide the implementation.

In our experience, the first requirement (buy in and ongoing support from senior leadership) is key to ensure that the implementation occurs with fidelity. Effective program buy in and support almost always is derived from organizations that have leadership and organizational cultures that are consonant with established principles that have been identified in organizations with excellent outcomes. ${ }^{79}$ The effective deployment of appropriately trained site champions typically requires one or two training approaches: 1) the champions receive a 1-day training and weekly support from an external entity, which is expert in both the targeted intervention and how to negotiate implementation of the intervention within a pharmacy setting or 2) the champions receive a 1-week training with ongoing support provided via established online learning communities or via a compendium of appropriate resources. The sites can choose which of these two approaches best fit their available resources. The pharmacist and other pharmacy staff training can be accomplished in a flexible manner so that pharmacists and allied staff are not away from their posts inordinately. For example, some of the training can be accomplished via online approaches, a series of staff development seminars, and even via on the job or hands-on activities.
It is sometimes difficult for pharmacies to collect the data necessary to guide the implementation of a targeted intervention. If the pharmacy lacks a sophisticated EHR or quality improvement platform, the implementation data may need to be collected using simple metrics (ie, number of patients who received an intervention per day) via tablets or paper forms. It is imperative that all of the staff involved with the project review the carefully chosen metrics in as close to real time as possible so that course corrections can be designed and tested when indicated in as close to the time when the implementation problems are identified. It is the champions' responsibility to ensure that this data review and testing of course correction strategies take place, but it is imperative that the champions receive support from their management to conduct this work and have the flexibility to make changes in the implementation strategies as indicated by the data.

Other barriers to implementing adherence interventions within a pharmacy setting include clashes between how the pharmacists view their roles versus how their roles might need to change to conduct the interventions. These changes in pharmacist roles and responsibilities are included but are not limited to periods of flu immunization, which result in providing the pharmacists less time to conduct other interventions; changes in requirements by payers that can take time and resources away from the targeted implementation; and changes in staff (management or front line pharmacists), which require the provision of additional training and support. All of these barriers can be obviated by organizational leadership, which is focused on the program vision and applies targeted principles that permit the organization to embrace attitudes and beliefs that support its desire to continuously learn how to achieve clinical excellence for every patient to which it provides services.

\section{Conclusion}

In conclusion, the literature is replete with many community pharmacy-led innovations that have had varying degrees of success. We have offered a framework for community pharmacy adherence interventions that we believe will lead to greater and consistent success as measured by improved medication adherence. The opportunity is here now for community pharmacy experts and leadership to develop consensus on best practice for improving medication adherence in community-dwelling patients that includes an implementation framework.

\section{Disclosure}

The authors report no conflicts of interest in this work. 


\section{References}

1. Osterberg L, Blaschke T. Adherence to medication. $N$ Engl J Med. 2005;353(5):487-497.

2. Ho PM, Bryson CL, Rumsfeld JS. Medication adherence: its importance in cardiovascular outcomes. Circulation. 2009;119(23):3028-3035.

3. Yeaw J, Benner JS, Walt JG, Sian S, Smith DB. Comparing adherence and persistence across 6 chronic medication classes. J Manag Care Pharm. 2009;15(9):728-740.

4. Choudhry NK, Glynn RJ, Avorn J, et al. Untangling the relationship between medication adherence and post-myocardial infarction outcomes: medication adherence and clinical outcomes. Am Heart J. 2014;167(1):51-58. e55.

5. Kuntz JL, Safford MM, Singh JA, et al. Patient-centered interventions to improve medication management and adherence: a qualitative review of research findings. Patient Educ Couns. 2014;97(3):310-326.

6. Rasmussen JN, Chong A, Alter DA. Relationship between adherence to evidence-based pharmacotherapy and long-term mortality after acute myocardial infarction. JAMA. 2007;297(2):177-186.

7. Egede LE, Gebregziabher M, Dismuke CE, et al. Medication nonadherence in diabetes longitudinal effects on costs and potential cost savings from improvement. Diabetes Care. 2012;35(12):2533-2539.

8. Roebuck MC, Liberman JN, Gemmill-Toyama M, Brennan TA. Medication adherence leads to lower health care use and costs despite increased drug spending. Health Aff. 2011;30(1):91-99.

9. Sokol MC, McGuigan KA, Verbrugge RR, Epstein RS. Impact of medication adherence on hospitalization risk and healthcare cost. Med Care. 2005;43(6):521-530.

10. Pringle JL, Boyer A, Conklin MH, McCullough JW, Aldridge A. The Pennsylvania project: pharmacist intervention improved medication adherence and reduced health care costs. Health Aff. 2014;33(8):1444-1452.

11. Taitel M, Jiang J, Rudkin K, Ewing S, Duncan I. The impact of pharmacist face-to-face counseling to improve medication adherence among patients initiating statin therapy. Patient Prefer Adherence. 2012;6:323-329.

12. Van Boven JF, Stuurman-Bieze AG, Hiddink EG, Postma MJ, Vegter S. Medication monitoring and optimization: a targeted pharmacist program for effective and cost-effective improvement of chronic therapy adherence. J Manag Care Spec Pharm. 2014;20(8):786-792.

13. Community Pharmacy Medicines Management Project Evaluation Team. The MEDMAN study: a randomized controlled trial of community pharmacy-led medicines management for patients with coronary heart disease. Fam Pract. 2007;24(2):189-200.

14. Kooy MJ, van Wijk BL, Heerdink E, de Boer A, Bouvy ML. Does the use of an electronic reminder device with or without counseling improve adherence to lipid-lowering treatment? The results of a randomized controlled trial. Front Pharmacol. 2013;4:69.

15. National Community Pharmacists Association. Medication Adherence in America: A National Report. Alexandria, VA: National Community Pharmacists Association; 2013.

16. Institute of Medicine. Committee on Quality of Health Care in America. Crossing the Quality Chasm: A New Health System for the 21st Century. Washington, DC: National Academy Press; 2001.

17. Center for Substance Abuse Prevention. Identifying and selecting evidence-based interventions revised guidance document for the strategic prevention framework state incentive grant program. Rockville, MD: Center for Substance Abuse Prevention, Substance Abuse and Mental Health Services Administration; 2009. Available from https://store. samhsa.gov/shin/content/SMA09-4205/SMA09-4205.pdf. Accessed October 29, 2015.

18. Schillinger D. An introduction to Effectiveness, Dissemination and Implementation Research. UCSF Clinical and Translational Science Institute (CTSI) Resource Manuals and Guides to Community-Engaged Research. Vol 28. San Francisco, CA: University of California San Francisco; 2014.

19. Krueger KP, Felkey BG, Berger BA. Improving adherence and persistence: a review and assessment of interventions and description of steps toward a national adherence initiative. J Am Pharm Assoc. 2003;43(6):668-679.
20. Horsburgh M, Lamdin R, Williamson E. Multiprofessional learning: the attitudes of medical, nursing and pharmacy students to shared learning. Med Educ. 2001;35(9):876-883.

21. Aag T, Garcia BH, Viktil KK. Should nurses or clinical pharmacists perform medication reconciliation? A randomized controlled trial. Eur J Clin Pharmacol. 2014;70(11):1325-1332.

22. Bond C, Raehl CL, Franke T. Clinical pharmacy services, pharmacy staffing, and the total cost of care in United States hospitals. Pharmacotherapy. 2000;20(6):609-621.

23. Reeder TA, Mutnick A. Pharmacist-versus physician-obtained medication histories. Am J Health Syst Pharm. 2008;65(9):857-860.

24. O’Neal KS, Crosby KM, Miller MJ, Murray KA, Condren ME. Assessing health literacy practices in a community pharmacy environment: experiences using the AHRQ pharmacy health literacy assessment tool. Res Social Adm Pharm. 2013;9(5):564-596.

25. Butterworth SW. Influencing patient adherence to treatment guidelines. J Manag Care Pharm. 2008;14(6 Suppl B):21-24.

26. Ables A, Baughman O 3rd. The clinical pharmacist as a preceptor in a family practice residency training program. Fam Med. 2002;34(9): 658-662.

27. Tsuyuki RT, Schindel TJ. Changing pharmacy practice: the leadership challenge. Can Pharm J. 2008;141(3):174-180.

28. Unni EJ, Farris KB. Unintentional non-adherence and belief in medicines in older adults. Patient Educ Couns. 2011;83(2):265-268.

29. McHorney CA, Gadkari AS. Individual patients hold different beliefs to prescription medications to which they persist vs nonpersist and persist vs nonfulfill. Patient Prefer Adherence. 2010;4:187.

30. Atkins L, Fallowfield L. Intentional and non-intentional non-adherence to medication amongst breast cancer patients. Eur J Cancer. 2006; 42(14):2271-2276.

31. Becker MH, Maiman LA. Sociobehavioral determinants of compliance with health and medical care recommendations. Med Care. 1975;13(1): $10-24$.

32. Sharkness C, Snow D. The patient's view of hypertension and compliance. Am J Prev Med. 1991;8(3):141-146.

33. Riegel B, Carlson B. Facilitators and barriers to heart failure self-care. Patient Educ Couns. 2002;46(4):287-295.

34. Wu J-R, Moser DK, Lennie TA, Burkhart PV. Medication adherence in patients who have heart failure: a review of the literature. Nurs Clin North Am. 2008;43(1):133-153.

35. Hicks FD, Holm K. Self-management decision influences in heart failure a preliminary investigation. Clin Nurs Res. 2003;12(1):69-84.

36. Eriksson T. Evidence-based and pragmatic steps for pharmacists to improve patient adherence. Integr Pharm Res Pract. 2015;4:13-19.

37. Hawkings NJ, Butler CC, Wood F. Antibiotics in the community: a typology of user behaviours. Patient Educ Couns. 2008;73(1): 146-152.

38. Vervloet M, Linn AJ, van Weert JC, De Bakker DH, Bouvy ML, Van Dijk L. The effectiveness of interventions using electronic reminders to improve adherence to chronic medication: a systematic review of the literature. J Am Med Inform Assoc. 2012;19(5):696-704.

39. Touchette DR, Shapiro NL. Medication compliance, adherence, and persistence: current status of behavioral and educational interventions to improve outcomes. J Manag Care Pharm. 2008;14(6):S2-S10.

40. Pringle J, Melczak M, Aldridge A, Snyder M, Smith R. Medication Adherence and its Relationship to the Therapeutic Alliance: Results from an Innovative Pilot Study Within a Community Pharmacy MTM Practice. University of Minnesota: Minneapolis, MN. 2011.

41. Krummenacher I, Cavassini M, Bugnon O, Schneider MP. An interdisciplinary HIV-adherence program combining motivational interviewing and electronic antiretroviral drug monitoring. AIDS Care. 2011;23(5):550-561.

42. Levensky ER, Forcehimes A, O’Donohue WT, Beitz K. Motivational Interviewing: an evidence-based approach to counseling helps patients follow treatment recommendations. Am J Nurs. 2007;107(10):50-58.

43. Murray MD, Young J, Hoke S, et al. Pharmacist intervention to improve medication adherence in heart failure: a randomized trial. Ann Intern Med. 2007;146(10):714-725. 
44. Haynes RB, Ackloo E, Sahota N, McDonald HP, Yao X. Interventions for enhancing medication adherence. Cochrane Database Syst Rev. 2008;(2):CD000011.

45. Girvin BG, Johnston GD. Comparison of the effects of a 7-day period of non-compliance on blood pressure control using three different antihypertensive agents. J Hypertens. 2004;22(7):1409-1414.

46. Holland R, Lenaghan E, Harvey I, et al. Does home based medication review keep older people out of hospital? The HOMER randomised controlled trial. BMJ. 2005;330(7486):293.

47. Stewart S, Marley JE, Horowitz JD. Effects of a multidisciplinary, home-based intervention on planned readmissions and survival among patients with chronic congestive heart failure: a randomised controlled study. Lancet. 1999;354(9184):1077-1083.

48. Munger MA, Van Tassell BW, LaFleur J. Medication nonadherence: an unrecognized cardiovascular risk factor. MedGenMed. 2007;9(3):58.

49. Pop-Eleches C, Thirumurthy H, Habyarimana JP, et al. Mobile phone technologies improve adherence to antiretroviral treatment in a resourcelimited setting: a randomized controlled trial of text message reminders AIDS. 2011;25(6):825-834.

50. Vollmer WM, Feldstein A, Smith D, et al. Use of health information technology to improve medication adherence. Am J Manag Care. 2011; 17(12 Spec No):S79

51. DiMatteo MR. Variations in patients' adherence to medical recommendations: a quantitative review of 50 years of research. Med Care 2004;42(3):200-209.

52. Morisky DE, Ang A, Krousel-Wood M, Ward HJ. Predictive validity of a medication adherence measure in an outpatient setting. $J$ Clin Hypertens. 2008;10(5):348-354

53. NEHI. Waste and Inefficiency in the US Health Care System. Clinical Care: A Comprehensive Analysis in Support of System-Wide Improvements New England Healthcare Institute: Cambridge, MA. 2008.

54. Stuart N, Adams J. The sustainability of Canada's healthcare system: a framework for advancing the debate. Healthc Q. 2006;10(2):96-103.

55. Przywara B. Projecting Future Health Care Expenditure at European Level: Drivers, Methodology and Main Results. Directorate General Economic and Monetary Affairs (DG ECFIN), European Commission: Brussels, Belgium; 2010.

56. Siegel JE, Weinstein MC, Russell LB, Gold MR. Recommendations for reporting cost-effectiveness analyses. JAMA. 1996;276(16):1339-1341.

57. Goetzel RZ, Ozminkowski RJ, Villagra VG, Duffy J. Return on investment in disease management: a review. Health Care Financ Rev. 2005;26(4):1.

58. Grosse SD, Teutsch SM, Haddix AC. Lessons from cost-effectiveness research for United States public health policy*. Annu Rev Public Health. 2007;28:365-391.

59. Chisholm-Burns MA, Graff Zivin JS, Lee JK, et al. Economic effects of pharmacists on health outcomes in the United States: a systematic review. Am J Health Syst Pharm. 2010;67(19):1624-1634.

60. Nieuwlaat R, Wilczynski N, Navarro T, et al. Interventions for enhancing medication adherence. Cochrane Database Syst Rev. 2014;11:CD000011.

61. Röhrig B, du Prel J-B, Wachtlin D, Blettner M. Types of study in medical research: part 3 of a series on evaluation of scientific publications. Dtsch Arztebl Int. 2009;106(15):262.

62. du Prel J-B, Röhrig B, Blettner M. Critical appraisal of scientific articles: part 1 of a series on evaluation of scientific publications. Dtsch Arztebl Int. 2009;106(7):100.

Integrated Pharmacy Research and Practice

\section{Publish your work in this journal}

Integrated Pharmacy Research and Practice is an international, peer-reviewed, open access, online journal, publishing original research, reports, reviews and commentaries on all areas of academic and professional pharmacy practice. This journal aims to represent the academic output of pharmacists and pharmacy practice with particular focus on integrated care. All papers are carefully
63. Santacroce SJ, Maccarelli LM, Grey M. Intervention fidelity. Nurs Res. 2004;53(1):63-66.

64. Schoenwald SK, Hoagwood K. Effectiveness, transportability, and dissemination of interventions: what matters when? Psychiatr Serv. 2001;52(9):1190-1197.

65. McHugh RK, Murray HW, Barlow DH. Balancing fidelity and adaptation in the dissemination of empirically-supported treatments: the promise of transdiagnostic interventions. Behav Res Ther. 2009; 47(11):946-953.

66. Wandersman A, Duffy J, Flaspohler P, et al. Bridging the gap between prevention research and practice: the interactive systems framework for dissemination and implementation. Am J Community Psychol. 2008;41(3-4):171-181.

67. Spray JW, Parnapy SA. Teaching patient assessment skills to doctor of pharmacy students: the TOPAS study. Am J Pharm Educ. 2007; 71(4):64.

68. American College of Clinical Pharmacy, Burke JM, Miller WA, et al. Clinical pharmacist competencies. Pharmacotherapy. 2008;28(6): 806-815.

69. Rao D. Skills development using role-play in a first-year pharmacy practice course. Am J Pharm Educ. 2011;75(5):84.

70. Martin BA, Bruskiewitz RH, Chewning BA. Effect of a tobacco cessation continuing professional education program on pharmacists' confidence, skills, and practice-change behaviors. J Am Pharm Assoc. 2010;50(1):9.

71. Billay D, Myrick F. Preceptorship: an integrative review of the literature. Nurse Educ Pract. 2008;8(4):258-266.

72. McDonough RP, Bennett MS. Improving communication skills of pharmacy students through effective precepting. Am J Pharm Educ. 2006;70(3):58.

73. Hattingh HL, King MA, Smith NA. An evaluation of the integration of standards and guidelines in community pharmacy practices. Pharm World Sci. 2009;31(5):542-549.

74. Fixsen DL, Naoom SF, Blase KA, Friedman R M, Wallace F. Implementation research: A synthesis of the literature. Tampa, FL: University of South Florida, Louis de la Parte Florida Mental Health Institute, The National Implementation Research Network. 2005. Available from: http://ctndisseminationlibrary.org/PDF/nirnmonograph.pdf. Accessed October 29, 2015.

75. Yuan CT, Bradley EH, Nembhard IM. A mixed methods study of how clinician 'super users' influence others during the implementation of electronic health records. BMC Med Inform Decis Mak. 2015; 15(1):26.

76. Rogers EM. Diffusion of Innovations. New York City, NY: Simon and Schuster; 2010.

77. Viswanathan M, Kahwati LC, Golin CE, et al. Medication therapy management interventions in outpatient settings: a systematic review and meta-analysis. JAMA Intern Med. 2015;175(1):76-87.

78. Basheti IA, Armour CL, Reddel HK, Bosnic-Anticevich SZ. Long-term maintenance of pharmacists' inhaler technique demonstration skills. Am J Pharm Educ. 2009;73(2):32.

79. Hill LH, Delafuente JC, Sicat BL, Kirkwood CK. Development of a competency-based assessment process for advanced pharmacy practice experiences. Am J Pharm Educ. 2006;70(1):1.

peer reviewed to ensure the highest standards as well as ensuring that we are informing and stimulating pharmaceutical professionals. The manuscript management system is completely online and includes a very quick and fair peer-review system, which is all easy to use. Visit http://www.dovepress.com/ testimonials.php to read real quotes from published authors. 